\title{
SOSIALISASI BUSINESS PLAN MENINGKATKAN KAPASISTAS BUMDES SARI ARTHA BARENG JOMBANG
}

\author{
Dwi Ermayanti Susilo'), Wisnu Mahendri'2) \\ ${ }^{1)}$ STIE PGRI Dewantara Jombang, ${ }^{2)}$ Universitas KH. A. Wahab Hasbullah \\ ${ }^{1)}$ dwi.stiedw@gmail.com, ${ }^{2)}$ wisnu@unwaha.ac.id
}

\begin{tabular}{|c|c|}
\hline Histori artikel & Abstrak \\
\hline $\begin{array}{l}\text { Received: } \\
\text { 18 Maret } 2021 \\
\\
\text { Accepted: } \\
16 \text { April } 2021 \\
\\
\text { Published: } \\
19 \text { April } 2021\end{array}$ & $\begin{array}{l}\text { Tujuan pengabdian ini adalah sebagai alternatif untuk mengatasi } \\
\text { permasalahan-permasalahan yang sedang dihadapi oleh } \\
\text { BUMDes Sari Artha dimana BUMDes Sari Artha masih takut untuk } \\
\text { mengambil resiko dalam perencanaan-perencanaan yang sudah } \\
\text { direncanakan selain itu dengan adanya business plan } \\
\text { tersebut sekaligus juga sebagai alat untuk bekerja sama dengan } \\
\text { pihak ketiga dalam hal pendanaan, pembinaan, dam } \\
\text { pengembangannya agar usaha yang dijalankan dengan } \\
\text { kelayakan ekonomi, sosial dan lingkungan. Melalui program } \\
\text { pengabdian pada masyarakat kapasitas BUMDES dan } \\
\text { stakeholders dalam penyusunan business plan dapat ditingkatkan } \\
\text { melalui penyuluhan dan fasilitasi. Pemberikan edukasi tentang } \\
\text { pengelolaan atau pendampingan manajerial dan manajemen } \\
\text { resiko akan perencanaan-perencanaan tersebut. Metode yang } \\
\text { digunakan adalah melaksanakan kegiatan pengabdian ini adalah } \\
\text { berbentuk sosialisasi Business Plan dengan mengundang pihak } \\
\text { BUMDes serta perwakilan pengurus BUMDes. Hasil yang } \\
\text { diperoleh dari pelaksanaan pengadian kepada masyarakat ini } \\
\text { adalah pihak BUMDes Sari Artha diharapkan mampu } \\
\text { meningkatkan pengetahuan dan ketrampilan tentang teknik } \\
\text { penyusunan business plan, serta menghasilkan draft business } \\
\text { plan. }\end{array}$ \\
\hline
\end{tabular}

Kata-kata Kunci: sosialisasi business plan, kapasitas BUMDes 
Abstract. The purpose of this service is as an alternative to solve the problems that are near BUMDes Sari Artha where BUMDes Sari Artha is still afraid to take risks in plans that have been planned besides that with the existence of the business plan as well as a tool to work with third parties in terms of fostering and developing it so that the business is carried out with economic, social and environmental feasibility. Through community service programs, the capacity of BUMDES and stakeholders in the preparation of business plans can be improved through outreach and facilitation. Provide education on management or managerial assistance and risk management for these plans. The method used is to carry out this service activity is a form of Business Plan socialization by inviting BUMDes and BUMDes management representatives. The results obtained from the implementation of this service to the community are the BUMDes Sari Artha that BUMDes are able to increase knowledge and skills about business plan preparation techniques and produce draft business plan.

Keywords: Business Plan, BUMDes capasity

\section{PENDAHULUAN}

Suatu rencana kerja yang akan dibuat oleh BUMDes dalam bidang wirausaha harus dibuat secara tertulis dan resmi guna menjalankan kegiatan wirausahanya yaitu melalui (business plan). Business plan ini adalah alat yang sangat tepat dalam memegang kendali usaha dan menjaga agar pengusaha tersebut tetap berfokus pada usahanya dan tidak menyimpang. Selain itu untuk membentuk dan menumbuhkan jiwa kewirausahaan yang andal dan mampu membuat perencanaan bisnis (business plan) yang baik adalah hal yang tidak mudah oleh karena itu diperlukan usaha yang nyata dan serius. Pelaksanaan sosialisasi pembuatan business plan yang dilaksanakan dalam rangka pengabdian kepada masyarakat ini diharapkan dapat menjadi motivasi bagi masyarakat untuk menjadi seorang wirausahawan.

Business plan merupakan salah satu sarana sistematis dalam mempertajam ide bisnis. Dengan bantuan business plan, ide-ide bisnis akan lebih terencana dan sistematis. Melalui pendekatan-pendekatan standar business plan, akan diketahui siapa saja pasar atau konsumen potensial, bagaimana proses pemasarannya, serta bagaimana proses operasional dari bisnis yang sedang dijalani. Pada perencanaan finansial, akan diketahui bagaimana pemasukan dan pengeluaran yang paling optimal. Dengan bantuan komputer, akan dapat disimulasikan posisi pos-pos keuangan yang dapat menghasilkan profit yang tinggi bagi bisnis. Selain itu, tentu saja akan diketahui juga pos-pos bisnis mana saja yang tidak memberikan keuntungan dan bahkan bisa menjadi beban bisnis.

Menurut Solihin 2007, meskipun terdapat variasi dalam penyusunan rencana bisnis, tetapi sebuah rencana bisnis yang baik sekurang-kurangnya akan mencantumkan tujuh elemen pokok, yaitu : 1. Ringkasan eksekutif yang merangkum secara singkat seluruh isi rencana bisnis baik yang menyangkut tujuan usaha, strategi usaha, tujuan penyusunan rencana bisnis, uraian umum usaha, rencana pemasaran, rencana produksi, rencana keuangan, dan risiko-risiko usaha di masa depan. 2. Uraian umum usaha general business description yang akan dijalankan. 
Berdasarkan penjabaran pernyataan tersebut diatas, maka fokus pengabdian pada masyarakat ini mengambil judul Sosialisasi Business Plan Dalam Meningkatkan Kapasitas BUMDes Sari Artha Jombang.

\section{METODE PELAKSANAAN}

Metode yang digunakan dalam kegiatan Pengabdian Kepada Masyarakat meliputi wawancara, sosialisasi, dan pelatihan. Wawancara digunakan untuk mengetahui permasalahan BUMDes dan mitra dalam proses pembuatan Business Plan. Metode wawancara ini dilaksanakan secara online melalui aplikasi Whatsapp. Metode sosialisasi dan pelatihan digunakan pada saat pelaksanaan pengabdian kepada masyarakat. Pelaksanaan kegiatan ini dilakukan dalam tiga tahap, yaitu tahap persiapan, pelaksanaan, dan evaluasi. Tahap pertama adalah tahap persiapan. Dalam tahap ini tim melakukan survei pendahuluan untuk mengetahui kondisi target kegiatan dengan menganalisis kondisi tempat yang akan digunakan, kondisi peserta yang akan diberikan pelatihan, dan menyusun rancangan kegiatan yang akan dilakukan. Tahap kedua yaitu tahap pelaksanaan. Tim melakukan sosialisasi dan pelatihan. Tahap ketiga adalah monitoring dan evaluasi. Evaluasi kegiatan ini dilakukan terhadap proses kegiatan.

\section{HASIL DAN PEMBAHASAN}

Membuat business plan sangatlah penting bagi setiap pengusaha. Para pemilik bisnis diajak bercerita dengan berargumen tentang bagaimana business plan yang diperlukan dimana dalam business plan tersebut berisi tentang : 1) Pembukaan pada plan / rencana bisnis. Jelaskan siapa yang menulis, kapan dan untuk tujuan apa, 2) Perkiraan dari rencana ( plan bisnis yang akan dijalankan, 3) Strategic Overview, 4) keadaan usaha, 5) Produk atau jasa apa yang ditawarkan 6) Target pasar, 7) Strategi penjualan, 8) TI yang digunakan, 9) Operasional dan keuangan, 10) Pendanaan, 12) resiko Usaha, 11) Implementasi dan Kesimpulan.

Pada dasarnya untuk pembuatan format business plan tidaklah baku, tergantung siapa yang akan membaca, ditujukan kepada siapa business plan dan siapa yang melaksanakan business plan tersebut. Business plan disusun dengan jangka waktu 3-5 tahun ke depan. Karena bertujuan untuk menjadi patokan perusahaan mencapai sasaran sekaligus mendapatkan pendanaan, business plan harus dilengkapi data yang dapat dipertanggungjawabkan kebenarannya. Data dapat berasal dari sumber eksternal, atau internal. Sumber eksternal mengacu pada data pihak luar yang relevan dengan usaha dan disediakan oleh pihak yang memiliki reputasi. Sementara sumber internal mengacu pada data hasil pengamatan yang kita lakukan. 
Terkait dengan situasi dan beberapa aspek yang ada BUMDes Sari Artha maka kegiatan yang dilakukan dalam kegiatan pengabdian masyarakat adalah :

1. Mengusulkan BMC dan membantu merealisasikan BMC apabila dibutuhkan. Business Model Canvas (BMC) ialah suatu kerangka kerja yang membahas model bisnis dengan disajikan dalam bentuk visual berupa kanvas lukisan, agar dapat dimengerti dan dipahami dengan mudah.

2. Model ini digunakan untuk menjelaskan, memvisualisasikan, menilai, dan mengubah suatu model bisnis, agar mampu menghasilkan kinerja yang lebih optimal. BMC dapat digunakan untuk semua lini bisnis tanpa terbatas sektor usahanya. BMC sangat membantu untuk mempercepat proses analisis kekuatan dan kekurangan bisnis. Dengan mengetahui kekuatan dan kelemahan, maka analisis kebutuhan dan profit dapat dilakukan dengan cepat. Business Model Canvas dapat menjelaskan hubungan sembilan elemen model bisnis yang digambarkan secara visual, sehingga inovasi yang dibuat pada model bisnis perusahaan akan lebih mudah dipahami dan dimengerti. Walaupun ada beberapa versi, kira-kira secara garis besar sebagai berikut (Kurniawan, 2020)

a. Value Proposition

Dalam bisnis selalu ada produk atau jasa yang akan ditawarkan. Dalam blok area Value Proposition mencakup produk atau layanan apa yang ditawarkan untuk calon customer.

b. Customer Segments

Customer Segments menjadi blok area yang paling utama karena dari pelanggan-lah kita akan mendapatkan pemasukan.

c. Channels

Channels merupakan sarana untuk menyampaikan nilai atau manfaat dari produk kepada customer segment.

d. Customer Relationship

Di dalam lingkup ini yang dinilai adalah bagaimana menjalin hubungan dengan pelanggan. Agar pelanggan tidak mudah berpaling ke bisnis yang lain, maka sangat penting untuk menjalin hubungan yang baik. Selain itu, diperlukan juga pengawasan yang ketat dan intensif.

e. Key activities

Key activities mencakup segala aktivitas yang harus dilakukan seorang pelaku bisnis untuk menghasilkan produk atau layanan yang baik dan memuaskan. Yang termasuk dalam lingkup ini adalah branding, packaging, pasaran internet dan lainnya. 


\section{f. Key Resources}

Yang termasuk dalam area Key Resources adalah berbagai sumber daya yang dimiliki pebisnis atau organisasi untuk mewujudkan proposisi nilai seperti manusia, brand, peralatan, dan teknologi.

g. Key Partnership

Key Partnership berisi pihak-pihak yang menjadi penentu terhadap jalannya suatu bisnis. Key Partnership mempengaruhi suksesnya suatu bisnis. Bisnis yang baik tidak hanya mampu menjalin hubungan dengan para pelanggan saja, tapi juga dengan pihak yang bersangkutan lainnya seperti pemasok dan tim pemasaran.

h. Revenue Stream

Model bisnis kanvas adalah mencakup langkah-langkah yang harus dikuasai oleh seorang pebisnis. Seperti pemanfaatan biaya iklan, langganan, penjualan retail, lisensi, dan sebagainya.

\section{i. Cost Structure}

Meliputi biaya-biaya apa saja yang harus dikeluarkan untuk membentuk, memproduksi dan memasarkan produk atau layanan bisnis. Dengan pengelolaan biaya yang benar, bisnis yang kita jalankan akan menjadi lebih efisien, hemat dan meminimalkan risiko kerugian.

Berikut Business Model Canvas yang diajukan oleh bidang inovasi :

a) BMC Mengenai Pasar Desa Sari Artha

\section{THE BUSINESS MODEL CANVAS}

+Design By : Kelompok 15 Design $\downarrow$; Pasar Desa Demanyar

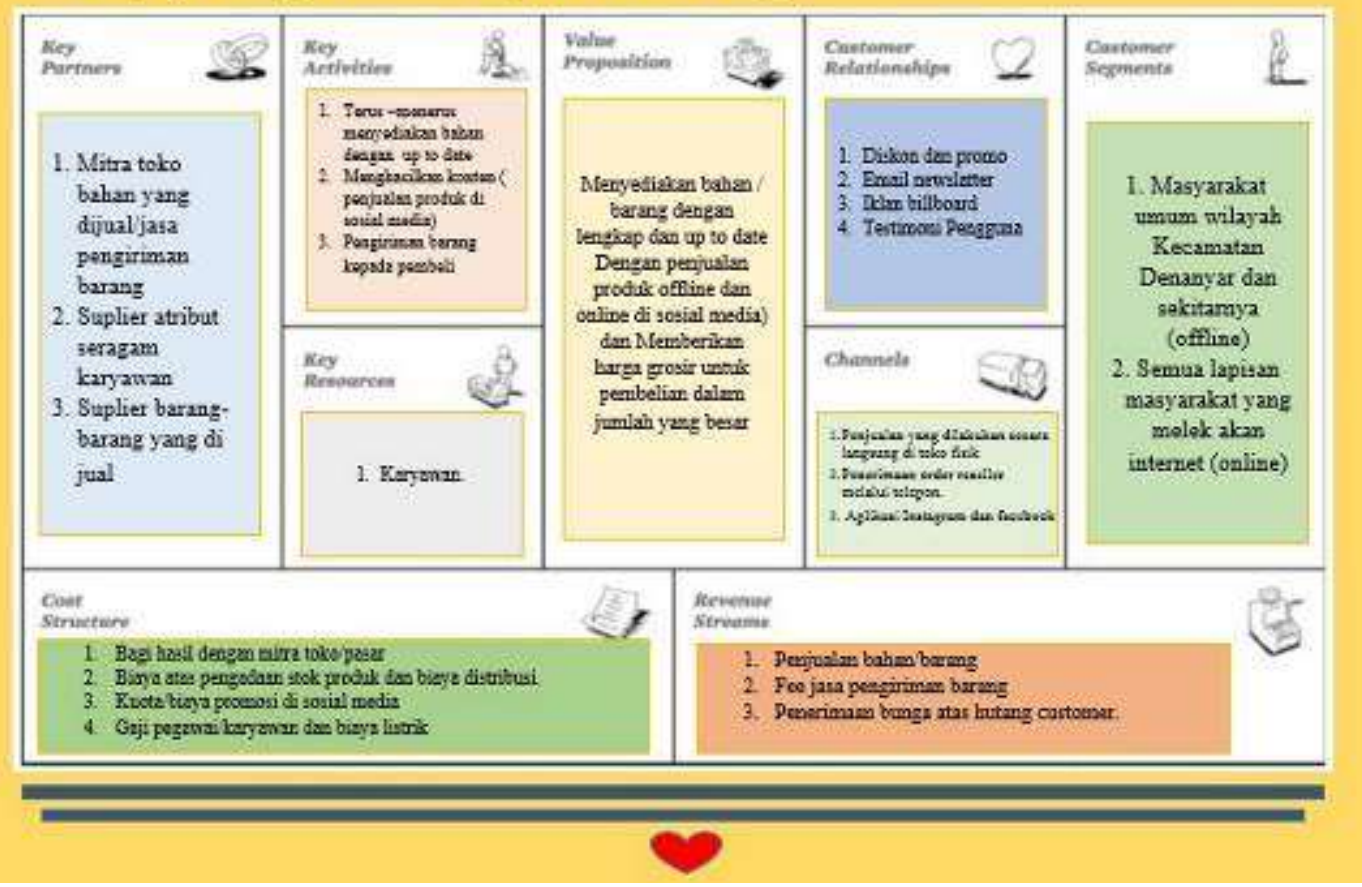

Gambar 1. BMC Pasar Desa Sari Artha 
b) BMC Mengenai Kampung Ucrit

THE BUSINESS MODEL CANVAS

$\downarrow$ Design By - Kelompok 15 Design $\downarrow$ Lumbung Desa

\begin{tabular}{|c|c|c|c|c|c|}
\hline $\begin{array}{l}\text { Key } \\
\text { Ririmen }\end{array}$ & $\begin{array}{l}\text { Koy } \\
\text { Activitiea }\end{array}$ & \multicolumn{2}{|l|}{$\begin{array}{l}\text { Yalue: } \\
\text { Propositioas }\end{array}$} & $\begin{array}{l}\text { Cuastomer } \\
\text { Relationnhips }\end{array}$ & $\begin{array}{l}\text { Cestomin } \\
\text { Segrmenta } \\
\text { 1. Masyarakat } \\
\text { umum wilayah } \\
\text { Kecamatan } \\
\text { Denaryar dan } \\
\text { sekitarnya } \\
\text { (offline) } \\
\text { 2. Semua lapisan } \\
\text { masyarakat yang } \\
\text { melek akan } \\
\text { internet (online) }\end{array}$ \\
\hline \multirow{2}{*}{$\begin{array}{l}\text { 1. Petani Desa } \\
\text { Denanyar } \\
\text { 2. Mitra toko beras } \\
\text { yang djualljasa } \\
\text { pengiriman } \\
\text { barang } \\
\text { 3. Suplier atribut } \\
\text { seragam } \\
\text { karyaman } \\
\text { 4. Suplier barang- } \\
\text { barang yang di } \\
\text { jual }\end{array}$} & 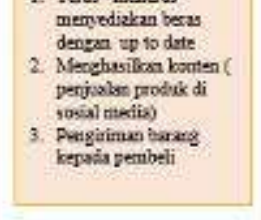 & \multirow{2}{*}{\multicolumn{2}{|c|}{$\begin{array}{l}\text { Nenyedialan beras } \\
\text { dengan lengkap dan } \\
\text { up to dote } \\
\text { Dengan penjualan } \\
\text { produk offline dan } \\
\text { online di sosial media) } \\
\text { den Membenikan } \\
\text { harga govir urtuk } \\
\text { pernbelian dalam } \\
\text { jumlah yomg besar }\end{array}$}} & $\begin{array}{l}\text { 1. Divan dan promo } \\
\text { 2. Email newnilatter } \\
\text { 3. Iflan billbard } \\
\text { 4. Tetimeni Pengguna }\end{array}$ & \multirow{2}{*}{$\begin{array}{l}\text { 1. Masyarakat } \\
\text { umum wilayah } \\
\text { Kecamatan } \\
\text { Denanyar dan } \\
\text { sekitarnya } \\
\text { (offline) } \\
\text { 2. Semua lapisan } \\
\text { masyarakat yang } \\
\text { melek akan } \\
\text { internet (online) }\end{array}$} \\
\hline & $\begin{array}{l}\text { 1. Karysasn Anegoh } \\
\text { 2. Petani }\end{array}$ & & & 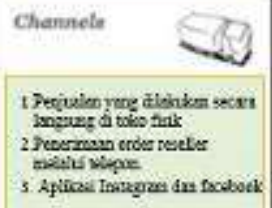 & \\
\hline \multicolumn{2}{|l|}{$\begin{array}{l}\text { Cout } \\
\text { Structure. }\end{array}$} & \multicolumn{2}{|c|}{$\begin{array}{l}\text { Revenar } \\
\text { Streitme }\end{array}$} & & \\
\hline \multicolumn{2}{|c|}{ 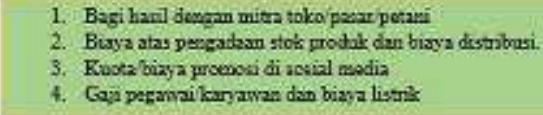 } & \multicolumn{4}{|c|}{$\begin{array}{l}\text { 1. Perjualan bahan barang } \\
\text { 2. Fee jasa penginman barang } \\
\text { 3. Pevermaan bunga stas hutang customer. }\end{array}$} \\
\hline
\end{tabular}

Gambar 2. BMC Kampung Ucrit

\section{THE BUSINESS MODEL CANVAS}

+ Design By : Kelompok 15

Design + Gedung Pertemuan

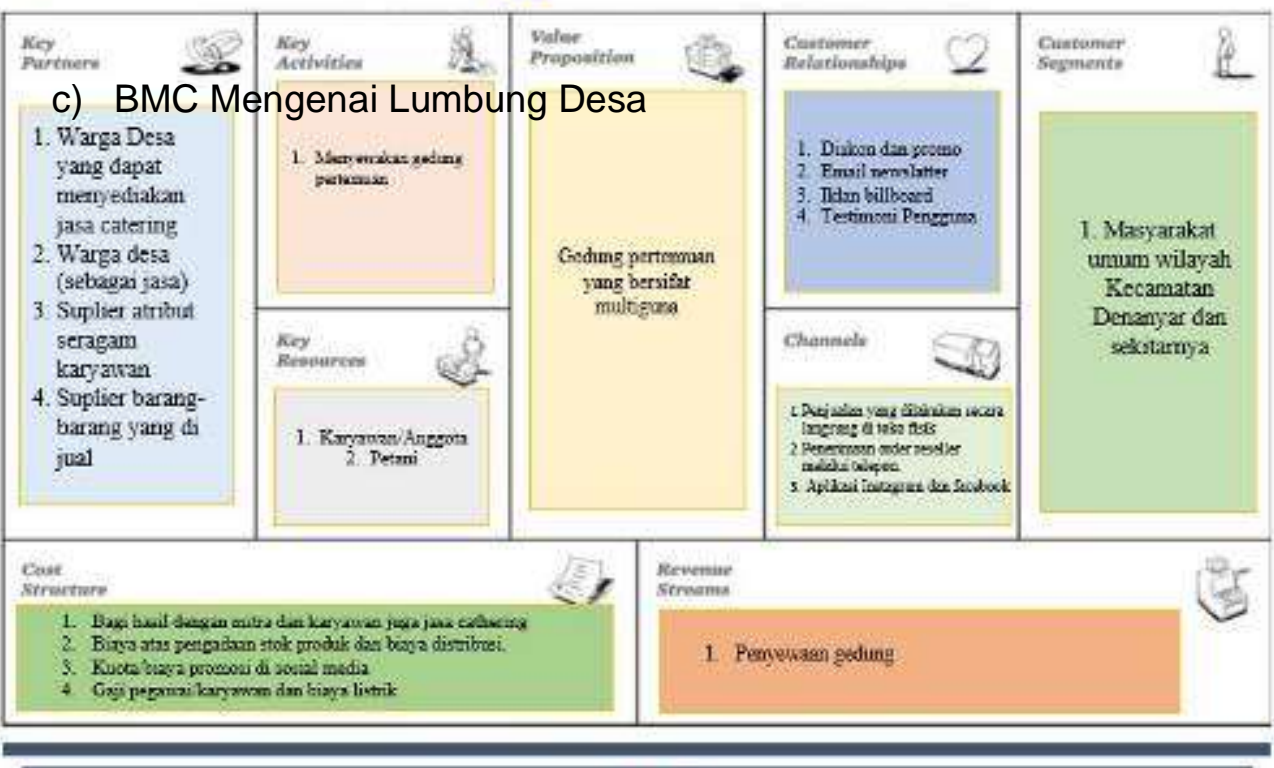

Gambar 3. BMC Lumbung Desa 
d) BMC Mengenai Gedung Pertemuan (Plan Baru)

\section{THE BUSINESS MODEL CANVAS}

+ Design By Kelompok 15 Design + : Kampung Uarit.

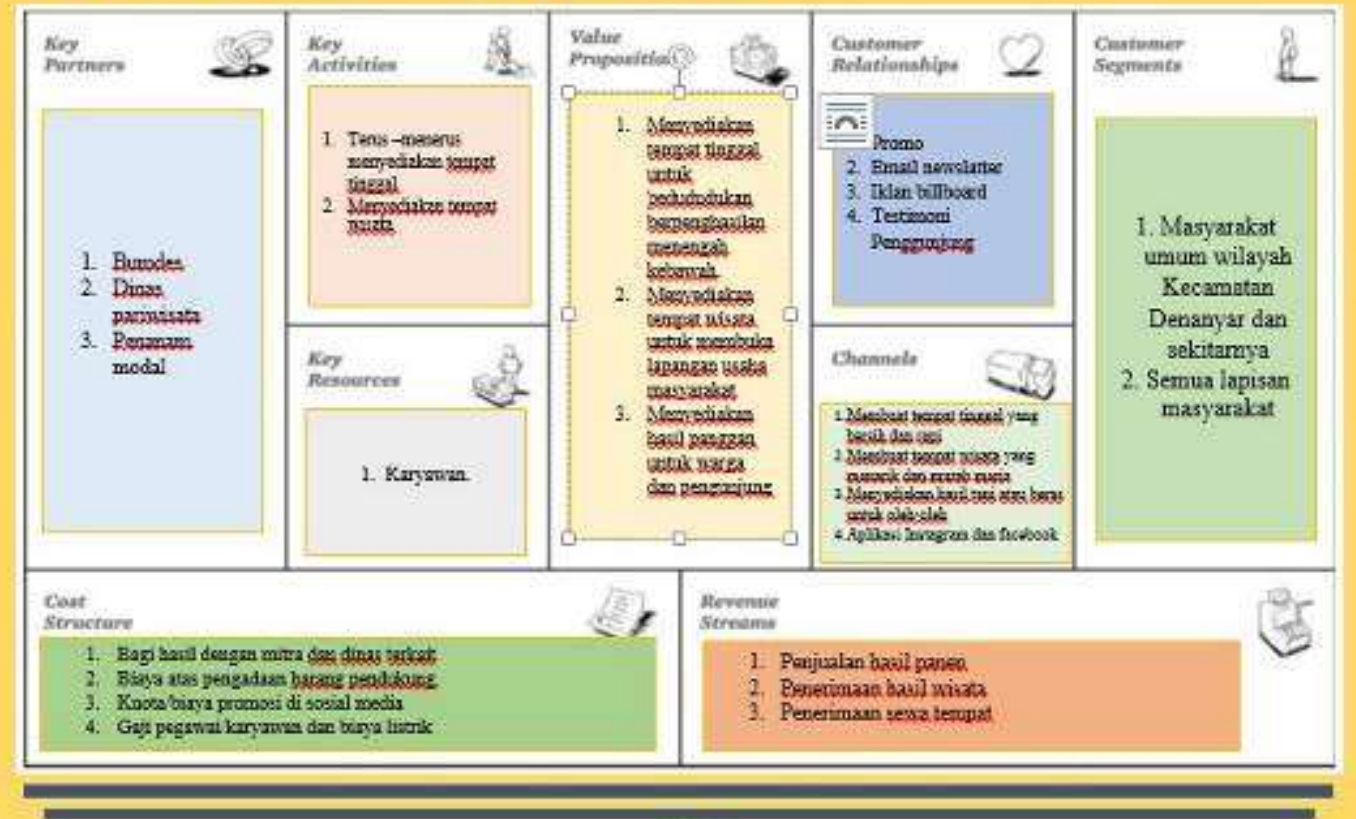

Gambar 4. BMC Gedung Pertemuan (Plan Baru)

\section{KESIMPULAN}

Dalam pelaksanaan kegiatan pengabdian tersebut antusias dari masyarakat dan BUMDes sangatlah baik. Hal ini dibuktikan dengan aktifkan peserta mengikuti kegiatan sosialisasi Business plan. Pada dasarnya, business plan adalah cetak biru dari konsep bisnis yang akan dibangun. Melalui rencana bisnis itu pulalah masyarakat dapat mengetahui tentang bagaimana cara merintis usaha dengan cermat dan bisa mencapai tujuan bisnis yang ingin diraih. Karena business plan adalah kunci utama agar bisnis bisa berjalan dengan sukses, intip paparannya berikut ini.

Diharapkan dalam pelaksanaan pengabdian berikutnya dapat melakukan program baru dan masih berkelanjutan yang masih terkait dengan lingkup BUMdes Sari Artha tetapi juga diperluas mengingat sebagai besar warga Desa Sari Artha berprofesi sebagai wirausaha. 


\section{DAFTAR PUSTAKA}

Kurniawan, K., 2020. Apa Itu Bisnis Model Canvas? Mengenal BMC. [Online] Available at: https://projasaweb.com/bisnis-model-canvas/ [Accessed 1 Maret 2021].

Laksmini, F. \& Budiantoro, 2008. Manajemen Perkantoran Modern. Jakarta: Penerbit Pernaka.

Oktaviani, G., 2019. Tugas Sistem Informasi Akuntansi: Implementasi Sistem Informasi Akuntansi Pada Gita Busana. [Online] Available at: https://www.researchgate.net/publication/335714238 TUGAS SISTEM IN FOR MASI AKUNTANSI IMPLEMENTASI SISTEM INFORMASI AKUNTANS I PADA GITA BUSANA [Accessed 1 Maret 2021].

Riadi, M., 2016. Pengertian, Tujuan, Fungsi dan Manfaat SOP. [Online] Available at: https://www.kajianpustaka.com/2016/10/pengertiantujuan-fungsi- dan-manfaat-sop.html? $m=1 p$ [Accessed 4 Maret 2021]. 